\title{
New Medium for the Production of Exopolysaccharide (OSKC) by Lactobacillus kefiranofaciens
}

\author{
Hiroaki MaEda, ${ }^{1 *}$ Xia Z $\mathrm{Hu}^{1}$ and Tomotari MitsuOKA ${ }^{2}$ \\ ${ }^{1}$ Research and Development Division, Daiwa Pharmaceutical Co., Ltd., 1-16-19, Sangenjaya, Setagaya-ku, Tokyo 154-0024, Japan \\ 2 Professor Emeritus, The University of Tokyo, 2-10-7, Sugano, Ichikawa 272-0824, Japan
}

Received October 24, 2002; Accepted for publication, March 7, 2003

Lactobacillus kefiranofaciens is known to produce an exopolysaccharide (kefiran) that is either excreted in the growth medium or attaches to the cell wall. In order to achieve high exopolysaccharide production, we developed a new rice hydrolyzate $(\mathbf{R H})$ medium using rice starch hydrolyzate as the carbon source and rice protein hydrolyzate as the peptone source. In this study, three fermentation experiments using RH medium, PYG10 medium and PYL10 medium were carried out, respectively. The highest amount of exopolysaccharide production was obtained from the culture grown in RH medium. Among the three various media compositions compared, rice protein hydrolyzate in the $\mathrm{RH}$ medium demonstrated the ability to significantly enhance exopolysaccharide production by $L$. kefiranofaciens. In addition, the cultivation of $L$. kefiranofaciens in a $500 l$ tank was also experimentally conducted, and the maximum yield of exopolysaccharide from the $\mathrm{RH}$ culture was $2.5 \mathrm{~g} / \mathrm{l}$ after a seven-day culture period at $\mathrm{pH} 5.0$ and $33^{\circ} \mathrm{C}$. This result indicates that it is possible to produce exopolysaccharide $(\mathrm{OSKC})$ at the level required for large-scale industrial production through the cultivation of $L$. kefiranofaciens in RH medium.

Key words: medium; rice hydrolyzate; Lactobacillus kefiranofaciens; exopolysaccharide

\section{INTRODUCTION}

Kefir is a popular fermented milk and one type of light alcoholic beverage. Kefir grains are usually used as a starter in the Caucasian regions. It is known that kefir grains consist of a gel matrix in which the microflora of yeasts and lactic acid bacteria are embedded $(1,9)$. Lactobacillus kefiranofaciens isolation from kefir grains has been reported to produce a water-soluble exopolysaccharide known as kefiran $(4,8,21)$. The exopolysaccharide produced by $L$. kefiranofaciens has a molecular weight of approximately $1.0 \times 10^{6}$, and is composed of a branched hexa- or heptasaccharide repeating unit containing approximately equal amounts of D-glucose and D-galactose residues. This structure is believed to be the same as that extracted from kefir grains $(6,11,12)$. The gel obtained from the kefiran solution lacked rigidity, but its strength could be improved by adding ethanol or mixing with either $\kappa$-carrageenan or xanthan gum. These gel-forming characteristics and rheological properties of kefiran showed that kefiran could serve as a food thickener $(13,17)$. On the other hand, previous studies on the oral admin-

\footnotetext{
*Corresponding author. Mailing address: Research and Development Division. Daiwa Pharmaceutical Co., Ltd., 1-16-19, Sangenjaya, Setagaya-ku, Tokyo 154-0024, Japan. Phone: +81-3-5430-4050. Fax: +81-3-3422-5399. E-mail: maeda@daiwa-pharm.com
}

istration of kefiran to mice have indicated that kefiran is effective for tumor growth and delayed-type hypersensitivity induced by picryl chloride $(14,15,18)$. Moreover, kefiran has also been demonstrated to have an enhancing effect on the production of interferon $\beta$ from animal cells suppressed by stress hormones cortisol and noradrenaline (5).

There are some reports dealing with the isolation of L. kefiranofaciens from kefir grains, and the pure culturing conditions required for exopolysaccharide production using Lactobacillus sp. (3, 4, 10, 20-22). However, previous studies relating to the cultivation of $L$. kefiranofaciens were carried out on a limited scale in laboratories. In this study, we experimentally developed a new medium, named "rice hydrolyzate $(\mathrm{RH})$ medium," to produce exopolysaccharide (OSKC) using a pure culture of $L$. kefiranofaciens. In the RH medium, the main components of the carbon and peptone sources were from rice hydrolyzate with a procedure in which the rice was first hydrolyzed by pepsin and then by glucoamylase. The cultivation of $L$. kefiranofaciens in each RH medium, PYG10 medium and PYL10 medium was separately examined. We also investigated the possibility of producing exopolysaccharide in a pure culture of $L$. kefiranofaciens using a $500 l$ tank.

\section{MATERIALS AND METHODS}

Bacterial strain and media. The strain L. kefirano- 
Table 1. Compositions of the experimental media.

\begin{tabular}{ccc}
\hline Rice hydrolyzate $(\mathrm{RH})$ medium & \multicolumn{1}{c}{ PYG10 medium } & \multicolumn{1}{c}{ PYL10 medium } \\
\hline $10 \%$ Rice starch hydrolyzate & $10 \%$ Glucose & $10 \%$ Lactose \\
$0.35 \%$ Rice protein hydrolyzate & $1.5 \%$ Polypepton & $1.5 \%$ Polypepton \\
$1 \%$ Yeast extract & $1 \%$ Yeast extract & $1 \%$ Yeast extract \\
$0.1 \%$ Tween 80 & $0.1 \% \mathrm{Tween} 80$ & $0.1 \%$ Tween 80 \\
$0.2 \% \mathrm{~K}_{2} \mathrm{HPO}_{4}$ & $0.2 \% \mathrm{~K}_{2} \mathrm{HPO}_{4}$ & $0.2 \% \mathrm{~K}_{2} \mathrm{HPO}_{4}$ \\
$0.5 \% \mathrm{Sodium}_{4}$ acetate & $0.5 \%$ Sodium acetate & $0.5 \%$ Sodium acetate \\
$0.2 \%$ Triammonium citrate & $0.2 \%$ Triammonium citrate & $0.2 \%$ Triammonium citrate \\
$0.02 \% \mathrm{MgSO}_{4} \cdot 7 \mathrm{H}_{2} \mathrm{O}$ & $0.02 \% \mathrm{MgSO}_{4} \cdot 7 \mathrm{H}_{2} \mathrm{O}$ & $0.02 \% \mathrm{MgO}_{4} \cdot 7 \mathrm{H}_{2} \mathrm{O}$ \\
$0.005 \% \mathrm{MnSO}_{4} \cdot 5 \mathrm{H}_{2} \mathrm{O}$ & $0.005 \% \mathrm{MnSO}_{4} \cdot 5 \mathrm{H}_{2} \mathrm{O}$ & $0.005 \% \mathrm{MnSO}_{4} \cdot 5 \mathrm{H}_{2} \mathrm{O}$ \\
\hline
\end{tabular}

faciens WT-2B ${ }^{\mathrm{T}}$ (JCM 6985 = ATCC 43761) was obtained from Tomohiko Fujisawa, Kanagawa Prefectural Public Health Laboratory, Yokohama, Japan. This strain was separately cultured in RH, PYG10, and PYL10 mediums. The compositions of the three experimental media are summarized in Table 1 . The $\mathrm{pH}$ of each medium was adjusted to 6.5 before autoclaving at $115^{\circ} \mathrm{C}$ for $20 \mathrm{~min}$.

Extraction and preparation of starch and protein fractions from rice. Commercial rice was obtained from a local market, and then powdered. The proteins contained in the rice were extracted twice with five volumes of $0.05 \mathrm{~N} \mathrm{NaOH}$ by stirring at $25^{\circ} \mathrm{C}$ for $3 \mathrm{hr}$. After centrifugation at $10,000 \times g$ for $20 \mathrm{~min}$, the precipitate collected was prepared for further experiments as the starch fraction. The supernatant obtained was fractionated with ammonium sulfate, and solid ammonium sulfate was added to the supernatant up to $100 \%$ saturation with continuous stirring. After being left for $1 \mathrm{hr}$, the resulting precipitate was collected by centrifugation at $10,000 \times g$ for $20 \mathrm{~min}$, and then dialyzed against distilled water. The dialyzate obtained was used in further experiments as the protein fraction.

Hydrolysis of rice starch by glucoamylase. The above-mentioned starch fraction was homogenized in 6-fold amounts (weight) of distilled water. The $\mathrm{pH}$ was then adjusted to 7.0 with $4 \mathrm{~N} \mathrm{HCl}$. After centrifugation at $10,000 \times g$ for $20 \mathrm{~min}$, lactic acid was added to the resulting precipitate to get a final concentration of $1 \%$ lactic acid, and then treated at $121^{\circ} \mathrm{C}$ for $30 \mathrm{~min}$. The solution obtained was enzymatically hydrolyzed by glucoamylase (EC 3.2.1.3, Sigma Chemical Co., USA, $0.2 \%$ of the rice weight) at $50^{\circ} \mathrm{C}$ and $\mathrm{pH}$ 4.5. Samples from the reaction mixture were taken at different indicated times and chromatographed on thin-layer plates of silica gel $70 \mathrm{~F}_{254}$ (Wako Pure Chemical Industries, Ltd., Japan) in a solvent system composed of $n$-butanol, pyridine, and distilled water $(8: 1: 1, \mathrm{v} / \mathrm{v})$. The separated samples were detected by ethanol-sulfuric acid $(1: 1, \mathrm{v} /$ v).

The reducing sugars contained in each sample from the reaction mixture were measured by the SomogyiNelson method (19) using glucose as the standard.

Hydrolysis of rice protein by pepsin and trypsin. The protein fraction was hydrolyzed by pepsin (EC 3.4.23.1, Wako, $0.012 \%$ of the rice weight) at $50^{\circ} \mathrm{C}, \mathrm{pH} 1.8$ and trypsin (EC 3.4.21.4, DIFCO Laboratories, USA, $0.48 \%$ of the rice weight) at $50^{\circ} \mathrm{C}, \mathrm{pH} 8.0$, respectively. Samples from each hydrolysis reaction were taken at different indicated times and examined by SDS-PAGE with a $20 \%$ SDS-polyacrylamide gel.

Growth and exopolysaccharide production in a culture broth of L. kefiranofaciens. The medium used for both the preparation of inocula and maintenance was MRS broth. L. kefiranofaciens was precultured in MRS broth at $33^{\circ} \mathrm{C}$ for $48 \mathrm{hr}$, and then inoculated into each experimental medium at an inoculum size of approximately $10^{6} \mathrm{CFU} / \mathrm{ml}$. After the removal of air by introducing carbon dioxide into the broth, $L$. kefiranofaciens was cultivated at $33^{\circ} \mathrm{C}$ for seven-day with the $\mathrm{pH}$ controlled at 5.0 by the addition of $5 \mathrm{~N}$ sodium hydroxide solution. The viable cell counts and levels of exopolysaccharide produced were determined.

The sample of cultured broth was suspended, and serially diluted 10 -fold in an anaerobic diluent $(0.45 \%$ $\mathrm{KH}_{2} \mathrm{PO}_{4}, 0.6 \% \mathrm{Na}_{2} \mathrm{HPO}_{4}, 0.05 \%$ cysteine hydrochloride, $0.05 \%$ Tween $80,0.1 \%$ bacto-agar). One-hundred microlitres of appropriate dilutions were cultured on plates of MRS agar (OXOID Ltd., UK) at $33^{\circ} \mathrm{C}$ for seven-day under anaerobic conditions established using an ANAERO PACK ANAERO (Mitsubishi Gas Chemical Co., Inc., Japan), and the colonies of $L$. kefiranofaciens were then counted.

To extract the total exopolysaccharide from both culture supernatant and capsulated cells, the culture was heated in a boiling water bath for $30 \mathrm{~min}$ and then cen- 
trifuged at $10,000 \times g$ for 15 min to remove the cells. The supernatant was collected, and then the exopolysaccharide was precipitated adding an equal volume of cold ethanol, followed by storage overnight at $4^{\circ} \mathrm{C}$. The precipitate was recovered by centrifugation at $10,000 \times g$ for $15 \mathrm{~min}$ and dissolved in distilled water. The exopolysaccharide was reprecipitated from the solution using the same procedure. The resulting precipitate was redissolved in distilled water, and carbohydrate contents were determined using an anthrone reagent that was prepared by dissolving anthrone $(0.2$ $\mathrm{g} / 100 \mathrm{ml})$ in $75 \%(\mathrm{v} / \mathrm{v})$ sulfuric acid. The sample $(0.5$ $\mathrm{ml})$ followed anthrone reagent $(5 \mathrm{ml})$ was slowly added to a test tube. The reaction mixture was then incubated in a boiling water bath for $10 \mathrm{~min}$ and immediately plunged into a cold-water bath, and finally the carbohydrate content was determined by optical density at $620 \mathrm{~nm}$ with lactose as the standard.

Protein assay. Protein concentration was measured using the method of Bradford (2) with bovine serum albumin as the standard.

SDS-PAGE. SDS-PAGE was performed using the method of Laemmli (7) with standard proteins (LMW Electrophoresis Calibration Kit, Amersham Pharmacia Biotech UK Ltd., UK) as the molecular mass markers. Protein bands were stained with silver (16).

\section{RESULTS}

\section{Hydrolysis of Starch}

In this study, the starch fraction extracted from rice was enzymatically hydrolyzed by glucoamylase at $50^{\circ} \mathrm{C}$ and $\mathrm{pH} 4.5$, and the reaction products obtained at the different indicated times were analyzed by TLC as shown in Fig. 1. In addition, the concentrations of reducing sugar for $0.5 \mathrm{hr}, 1 \mathrm{hr}$ and $2 \mathrm{hr}$ were 78.0, 92.2 and $97.9 \%$, respectively, based on the value for $5 \mathrm{hr}$ being $100 \%$. Rice starch hydrolyzate for the indicated

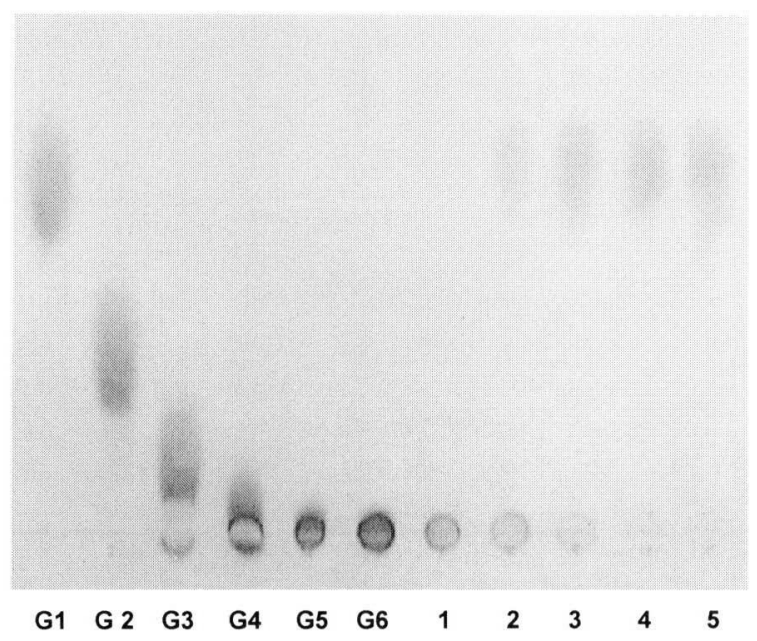

Fig. 1. TLC analysis of hydrolytic products from rice starch by glucoamylase.

The rice starch was incubated with glucoamylase at $50^{\circ} \mathrm{C}$ and $\mathrm{pH} 4.5$, and samples from the reaction mixture at the indicated times were analyzed by TLC.

Lanes: G1, glucose; G2, maltose; G3, maltotriose; G4, maltotetraose; G5, maltopentaose; G6, maltohexaose; 1, 0 hr; $2,0.5 \mathrm{hr} ; 3,1 \mathrm{hr} ; 4,2 \mathrm{hr} ; 5,5 \mathrm{hr}$.
A

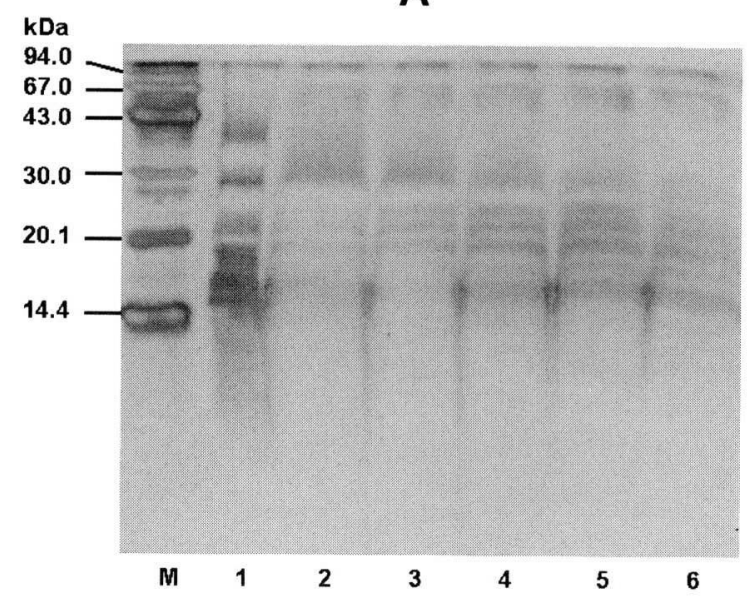

B

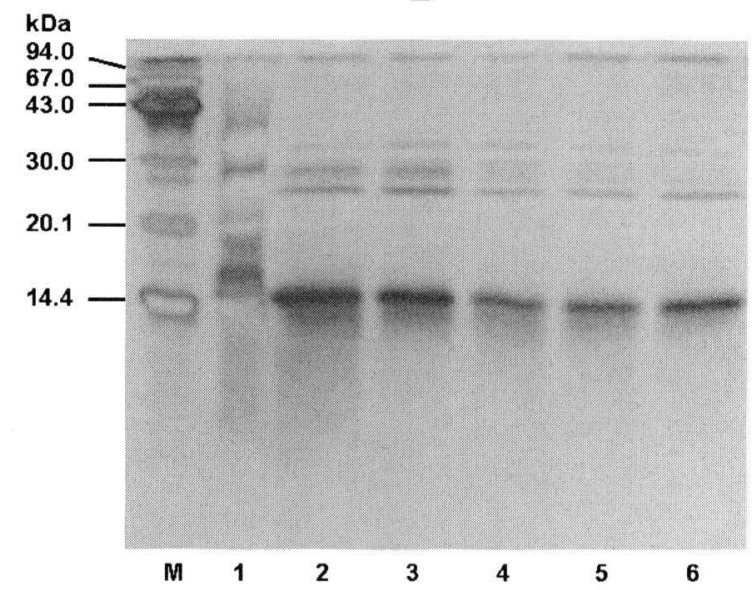

Fig. 2. SDS-PAGE of the enzymatic hydrolyzate of the rice protein.

Samples of the rice protein were hydrolyzed by pepsin (A) and trypsin (B), respectively, as described in Materials and Methods.

Lane M, molecular mass markers; lane 1 to 6 represent $0,1,2,3,4,5 \mathrm{hr}$, respectively, after the addition of pepsin (A) or trypsin (B). 
time of $2 \mathrm{hr}$ was used to prepare the $\mathrm{RH}$ medium due to the fact that the starch fraction was essentially hydrolyzed into glucose.

\section{Hydrolysis of Protein}

The protein fraction was hydrolyzed by pepsin $(0.012 \%$ of the rice weight $)$ and trypsin $(0.47 \%$ of the rice weight) at $50^{\circ} \mathrm{C}, \mathrm{pH} 1.8$ and $50^{\circ} \mathrm{C}, \mathrm{pH} 8.0$, respectively. The samples obtained at different indicated times up to $5 \mathrm{hr}$ were analyzed and compared with an untreated sample.

The hydrolysis of each individual protein presented in the protein fraction was estimated by $20 \%$ SDSPAGE (Fig. 2). The results showed that bands corresponding to high-molecular-weight proteins gradually disappeared during the incubation period, while those representing several peptidic fragments appeared.

The peptides digested by pepsin for $4 \mathrm{hr}$ were used to prepare the $\mathrm{RH}$ medium because the peptides generated after enzymatic cleavage of the proteins by pepsin had more extensive and varied band distributions (Fig. 2A) than those cleaved by trypsin (Fig. 2B). In addition, among the samples digested by pepsin for different times from $1 \mathrm{hr}$ to $5 \mathrm{hr}$ (Fig. 2A), the sample for 4 $\mathrm{hr}$ appeared to have the most peptides with low molecular weights between $14.4 \mathrm{kDa}$ and $30.0 \mathrm{kDa}$.

\section{Preparation of $R H$ Medium}

According to the results obtained in the hydrolysis of starch and protein, based on the purpose of making full use of the rice, a simplified procedure to prepare the RH medium without separating the rice into starch and protein fractions was set up. The rice was powdered and suspended in 6-fold amounts (weight) of distilled water, lactic acid was added to a final concentration of $1 \%$ lactic acid, and then the solution was treated at $121^{\circ} \mathrm{C}$ for $30 \mathrm{~min}$. The solution obtained was first hydrolyzed by pepsin at $50^{\circ} \mathrm{C}$ and $\mathrm{pH} 1.8$ for $4 \mathrm{hr}$, and then by glucoamylase at $50^{\circ} \mathrm{C}$ and $\mathrm{pH} 4.5$ for $2 \mathrm{hr}$. The hydrolyzate, consisting of $17.25 \%$ rice starch hydrolyzate and $0.60 \%$ rice protein hydrolyzate, was used to prepare the $\mathrm{RH}$ medium.

Comparison of Viable Cell Counts and Exopolysaccharide Production in the Experimental Media Cultured under Conditions Using a 5-l Jar Fermentor

L. kefiranofaciens was cultivated in $2.5 l$ of each experimental medium in $5-l$ jar fermentors (B. E. Marubishi Co., Ltd., Japan) at $\mathrm{pH} 5.0$ and $33^{\circ} \mathrm{C}$. As shown in Fig. 3, the growth of $L$. kefiranofaciens was about the same level for the three experimental media.
A

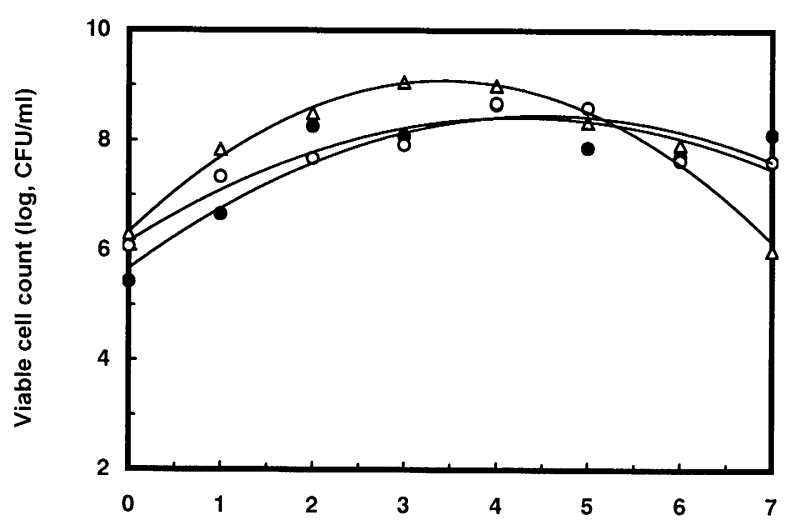

B

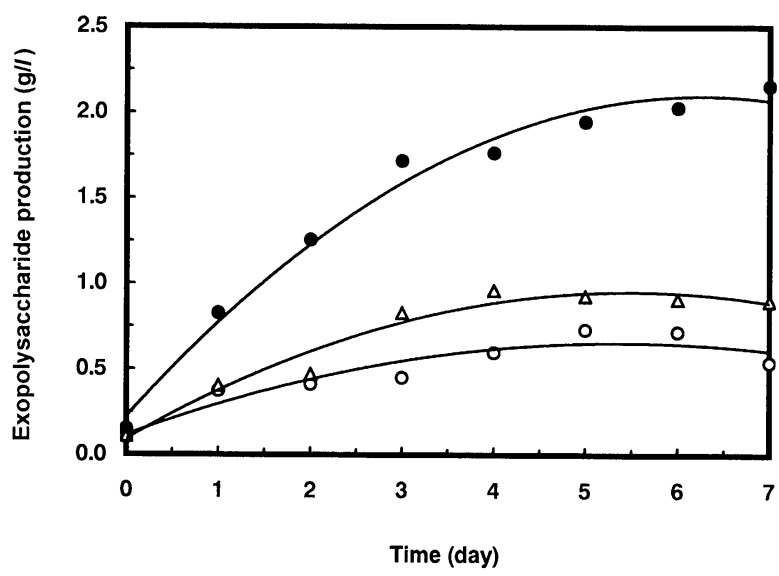

Fig. 3. Growth and exopolysaccharide production by $L$. kefiranofaciens in experimental media cultured in a $5-l \mathrm{jar}$ fermentor.

Cultivation was carried out in three different media. Symbols: (๑) RH medium, ( $\bigcirc$ ) PYG10 medium, ( $\triangle$ ) PYL10 medium.

The highest exopolysaccharide production was achieved in RH medium, even though the amount of rice protein hydrolyzate in the $\mathrm{RH}$ medium was 4.3 times lower than that of the polypepton in both PYG10 medium and PYL10 medium. In this research, the utilization of rice protein hydrolyzate in preparation of the RH medium played an important role for ensuring satisfactory results.

\section{Culture of L. kefiranofaciens in a 500-l Tank}

L. kefiranofaciens was cultured in $400 l$ of RH medium in a $500-l$ tank at $\mathrm{pH} 5.0$ and $33^{\circ} \mathrm{C}$. The maximum yield of the exopolysaccharide produced by $L$. kefiranofaciens was about $2.5 \mathrm{~g} / \mathrm{l}$ after a seven-day culturing period. This result was nearly equivalent to that 
obtained using RH medium in the $5-l$ jar fermentor.

\section{DISCUSSION}

Recently, there have been some reports regarding the media used in the cultivation of L. kefiranofaciens and optimum culture conditions for the production of exopolysaccharide $(3,10,20-24)$. Among the media used in these studies, KPL medium and IKPL medium contained an expensive component of white table wine. The yield of exopolysaccharide was only $20 \mathrm{mg} / \mathrm{l}$ of in the KPL culture and $80 \mathrm{mg} / \mathrm{l}$ in the IKPL culture $(20$, 21). MRSL medium was used for the production of kefiran by Lactobacillus sp. KPB-167B isolated from kefir grains. In this medium, trypton, yeast extract, meat extract and triammonium citrate were used as nitrogen sources, and lactose as the carbon source. The highest broth yield obtained was $2.04 \mathrm{~g} / \mathrm{l}$ (22). Modified MRSL medium also gave a yield of $2 \mathrm{~g} / 1$ of purified kefiran from the culture supernatant of the LM-17 strain that was a ropy Lactobacillus strain isolated from kefir grains (10). However, all of these studies were conducted on a limited scale in laboratories.

In the present study, utilizing traditional food rice as the peptone and carbon sources, we developed an RH medium that does not contain white table wine, trypton or meat extracts (Table 1). Using PYG10 medium as the basal medium, the polypepton and glucose in PYG10 medium were replaced with rice protein hydrolyzate and rice starch hydrolyzate, respectively. Therefore, a new medium was obtained for exopolysaccharide production.

Regarding the peptone source in each medium, polypepton (Nihon Seiyaku Co., Ltd., Japan) digested from casein by trypsin was used for preparing the PYG10 and PYL10 media, while the peptides from rice protein hydrolyzate were used for the RH medium. In comparing the PYG10 and PYL10 media for their abilities to grow L. kefiranofaciens and produce exopolysaccharide, the viable cell counts in PYL10 medium were found to be higher than those in PYG10 medium within four-day, and the yield of exopolysaccharide in PYL10 medium was higher than that in PYG10 medium throughout the entire seven-day culturing period. These results reveal that lactose used as the carbon source is more effective than glucose for growing L. kefiranofaciens and producing exopolysaccharide. This result is in good agreement with the results of a prior report (22). However, an interesting point was found: when RH medium is used to incubate $L$. kefiranofaciens, the highest level of exopolysaccharide production is achieved, even though the amount of rice protein hy- drolyzate $(0.35 \%)$ in the RH medium is 4.3 times less than that of the polypepton (1.5\%) in PYG10 and PYL10 media, and glucose from rice starch hydrolyzate (not lactose) was used as the carbon source in the RH medium (Table 1). As shown in Fig. 3B, the yield of exopolysaccharide in $\mathrm{RH}$ medium at $\mathrm{pH} 5.0$ for seven-day was $2.16 \mathrm{~g} / \mathrm{l}$, while the yields in PYG10 and PYL10 media were $0.54 \mathrm{~g} / \mathrm{l}$ and $0.90 \mathrm{~g} / \mathrm{l}$, respectively. These results suggest that the peptides from rice digested by pepsin are more effective in exopolysaccharide production than those from casein digested by trypsin.

As a continuing study aimed at the large-scale cultivation of L. kefiranofaciens for the mass-production of exopolysaccharide, pure culturing of L. kefiranofaciens using a 500-l tank was experimentally conducted, even though there were no related reports found. As a result, exopolysaccharide production at a rate of $2.5 \mathrm{~g} / \mathrm{l}$ was successfully achieved using L. kefiranofaciens in RH medium. This result suggests that it is possible to obtain effective industrial-scale production of exopolysaccharide using L. kefiranofaciens in $\mathrm{RH}$ medium.

In addition, compositional analysis, methylation analysis, specific rotation and ${ }^{1} \mathrm{H}$ and ${ }^{13} \mathrm{C}$ NMR spectroscopy revealed that the structure of exopolysaccharide from RH medium is essentially identical to that of kefiran reported in previous studies $(10,12)$. The details of these experiments will be reported elsewhere.

Because kefir and rice are both traditional foods, the high safety of exopolysaccharide kefiran produced by the process of using the L. kefiranofaciens strain isolated from kefir grains and $\mathrm{RH}$ medium that contained rice hydrolyzate could be considered. Physiological effects, such as change in blood pressure and blood serum lipids, resulting from exopolysaccharide (OSKC) produced by L. kefiranofaciens in RH medium are now being investigated in our laboratory. It is anticipated that kefiran can be applied more extensively.

\section{REFERENCES}

(1) Arihara K, Toba T, Adachi S. 1990. Immunofluorescence microscopic studies on distribution of Lactobacillus kefiranofaciens and Lactobacillus kefir in kefir grains. Int $\mathbf{J}$ Food Microbiol 11: 127-134.

(2) Bradford MM. 1976. A rapid and sensitive method for the quantitation of microgram quantities of protein utilizing the principle of protein-dye binding. Anal Biochem 72: 248254.

(3) Cheirsilp B, Shimizu H, Shioya S. 2001. Modelling and optimization of environmental conditions for kefiran production by Lactobacillus kefiranofaciens. Appl Microbiol 
Biotechnol 57: 639-646.

(4) Fujisawa T, Adachi S, Toba T, Arihara K, Mitsuoka T. 1988. Lactobacillus kefiranofaciens sp. nov. isolated from kefir grains. Int J Syst Bacteriol 38: 12-14.

(5) Kabayama S, Osada K, Tachibana H, Katakura Y, Shirahata $S$. 1997. Enhancing effects of food components on the production of interferon $\beta$ from animal cells suppressed by stress hormones. Cytotechnology 23: 119-125.

(6) Kooiman P. 1968. The chemical structure of kefiran, the water-soluble polysaccharide of the kefir grain. Carbohydr Res 7: 200-211.

(7) Laemmli UK. 1970. Cleavage of structural proteins during the assembly of the head of bacteriophage T4. Nature 227: 680-685.

(8) La Rivière JWM, Kooiman P. 1967. Kefiran, a novel polysaccharide produced in the kefir grain by Lactobacillus brevis. Arch Mikrobiol 59: 269-278.

(9) Marshall VM, Cole WM, Brooker BE. 1984. Observations on the structure of kefir grains and the distribution of the microflora. J Appl Bacteriol 57: 491-497.

(10) Micheli L, Uccelletti D, Palleschi C, Crescenzi V. 1999. Isolation and characterisation of a ropy Lactobacillus strain producing the exopolysaccharide kefiran. Appl Microbiol Biotechnol 53: 69-74.

(11) Mukai T, Toba T, Itoh T, Adachi S. 1988. Structural microheterogeneity of kefiran from kefir grains. Jpn J Zootech Sci 59: 167-176.

(12) Mukai T, Toba T, Itoh T, Adachi S. 1990. Structural investigation of the capsular polysaccharide from Lactobacillus kefiranofaciens $\mathrm{K}_{1}$. Carbohydr Res 204: 227-232.

(13) Mukai T, Watanabe N, Toba T, Itoh T, Adachi S. 1991. Gel-forming characteristics and rheological properties of kefiran. J Food Sci 56: 1017-1018.

(14) Murofushi M, Mizuguchi J, Aibara K, Matuhasi T. 1986. Immunopotentiative effect of polysaccharide from kefir grain, KGF-C, administered orally in mice. Immunopharmacology 12: 29-35.

(15) Murofushi M, Shiomi M, Aibara K. 1983. Effect of orally administered polysaccharide from kefir grain on delayedtype hypersensitivity and tumor growth in mice. Jpn J Med Sci Biol 36: 49-53.

(16) Oakley BR, Kirsch DR, Morris NR. 1980. A simplified ultrasensitive silver stain for detecting proteins in polyacrylamide gels. Anal Biochem 105: 361-363.

(17) Pintado ME, Da Silva JAL, Fernandes PB, Malcata FX, Hogg TA. 1996. Microbiological and rheological studies on Portuguese kefir grains. Int J Food Sci Technol 31: 1526.

(18) Shiomi M, Sasaki K, Murofushi M, Aibara K. 1982. Antitumor activity in mice of orally administered polysaccharide from kefir grain. Jpn J Med Sci Biol 35: 75-80.

(19) Somogyi M. 1952. Notes on sugar determination. J Biol Chem 195: 19-23.

(20) Toba T, Abe S, Adachi S. 1987. Modification of KPL medium for polysaccharide production by Lactobacillus $\mathrm{sp}$. isolated from kefir grain. Jpn J Zootech Sci 58: 987-990.

(21) Toba T, Abe S, Arihara K, Adachi S. 1986. A medium for the isolation of capsular bacteria from kefir grains. Agr Biol Chem 50: 2673-2674.

(22) Yokoi H, Watanabe T. 1992. Optimum culture conditions for production of kefiran by Lactobacillus sp. KPB-167B isolated from kefir grains. J Ferment Bioeng 74: 327-329.

(23) Yokoi H, Watanabe T, Fujii Y, Mukai T, Toba T, Adachi S. 1991. Some taxonomical characteristics of encapsulated Lactobacillus sp. KPB-167B isolated from kefir grains and characterization of its extracellular polysaccharide. Int $\mathbf{J}$ Food Microbiol 13: 257-264.

(24) Yokoi H, Watanabe T, Fujii Y, Toba T, Adachi S. 1990. Isolation and characterization of polysaccharide-producing bacteria from kefir grains. J Dairy Sci 73: 1684-1689. 